\title{
Biosensors for the Environment
}

\author{
C. Malandain ${ }^{1}$, F. Fayolle ${ }^{1}$ and H. Bedouelle ${ }^{2}$ \\ 1 Institut français du pétrole, Département Biotechnologie et Chimie de la Biomasse, \\ 1 et 4, avenue de Bois-Préau, 92852 Rueil-Malmaison Cedex - France \\ 2 Institut Pasteur, Unité de Prévention et Thérapie Moléculaires des Maladies Humaines, CNRS, URA 2185 \\ 28, rue du Docteur-Roux, 75724 Paris Cedex 05 - France \\ e-mail: cedric.malandain@ifp.fr - francoise.fayolle@ifp.fr - hbedovel@pasteur.fr
}

Résumé - Biocapteurs pour l'environnement — La présence de polluants d'origine industrielle ou agricole dans l'environnement, et dans les eaux en particulier, est liée à l'utilisation massive de composés tels que les herbicides et pesticides, les solvants chlorés ainsi que les composés des essences qui peuvent être déversés lors du transport et du stockage des carburants. Les composés chimiques concernés sont généralement toxiques pour l'homme et les animaux. Cette toxicité nécessite dans les cas de pollution de suivre l'évolution de ces composés (en particulier en cas de menace sur des captages d'eau potable). Les outils classiques de mesure (CPG, CPG/SM, etc.) sont très efficaces du point de vue de la sensibilité et de la reproductibilité mais leur utilisation nécessite d'effectuer des prélèvements sur site, de transporter les échantillons puis de les analyser au laboratoire. Les délais induits peuvent être rédhibitoires et les coûts ne sont pas négligeables quand de nombreux échantillons sont à analyser sur des périodes de temps longues. C'est pour ces raisons que de nouveaux appareils de mesure, biosenseurs ou biocapteurs, qui profitent de l'avancée des connaissances dans plusieurs domaines scientifiques et dans celui de la biologie en particulier, ont été conçus. Ils permettent la création d'outils analytiques aussi fiables mais plus sélectifs et peu encombrants, qui fournissent des mesures en temps réel sur le site étudié.

\footnotetext{
Abstract - Biosensors for the Environment - Numerous pollutants from industrial or agricultural origins are found in the environment, and especially in water. Compounds such as herbicides, pesticides, chlorinated solvents as well as compounds linked to petroleum utilization are frequently found as pollutants of aquifers. These chemicals are generally toxic for humans and animals and their presence in water must be monitored to avoid the contamination of drinking water sources. Classical analytical tools $(G C, G C / M S$, etc.) provide accurate, reproducible and sensitive determination of contaminant concentrations. Nevertheless, their use requires to take samples on the contaminated sites and to transport the samples to laboratory for analysis. Such handling of samples is time-consuming and expensive. Biosensors are new analytical tools, whose conception has benefited from advances in different scientific areas, and particularly in biology; they now allow the development of highly specific tools. They provide real-time determination and detection of very low concentrations of contaminant and they can be used directly on-site.
} 


\section{INTRODUCTION}

Regulation is becoming more and more severe regarding the release of pollutants in the environment. The management of industrial processes will require the increase of the measurements to ensure that possible releases of hazardous chemicals are under control. Moreover, the tolerance of consumers regarding the possible contamination of their environment by chemicals is getting lower and the availability in water will become a matter of great concern since it is now recognized that water resource will become one of the major problems in the future.

These facts should lead industry to develop new tools for selective and rapid responses to the release of hazardous chemicals in the environment, especially in water. Actually, even if classical tools of measurements (GC/MS, etc.) give accurate results at very low concentration, they are heavy devices and their use can induce delays which are mainly due to the transport of samples to the laboratory for analysis. Such delays are not compatible with the needs of rapid intervention, for example when drinking water resources are endangered. Moreover, the costs induced by the transport of samples can, in some cases, be of the same order of magnitude than the cost of sampling itself.

For about ten years, alternate tools for the measurement of various chemicals have been created and developed. Their invention, which is the result of advances in different scientific areas and requires an interdisciplinary cooperation, is based on:

- new scientific knowledge in biology and biochemistry;

- the improvement of tools for the detection and amplification of physical or electrochemical signals leading to increasing capacities;

- the technical advances in science of materials linked to the progress in miniaturization for immobilization and packaging of biological substances.

\section{WHAT IS A BIOSENSOR?}

\subsection{Definition}

A biosensor transforms a specific molecular signal into an electric signal, and comprises several modules:

- a recognition module, which can be biological or biomimetic;

- a transduction module, which tranforms the recognition event into a measurable signal;

- and a module of data evaluation.

The recognition and transduction modules are integrated into a compact device (Fig. 1). A biosensor can function without addition of reagent, provide quantitative analytical informations, and follow the concentration of an analyte continuously. Important characteristics of a biosensor are the

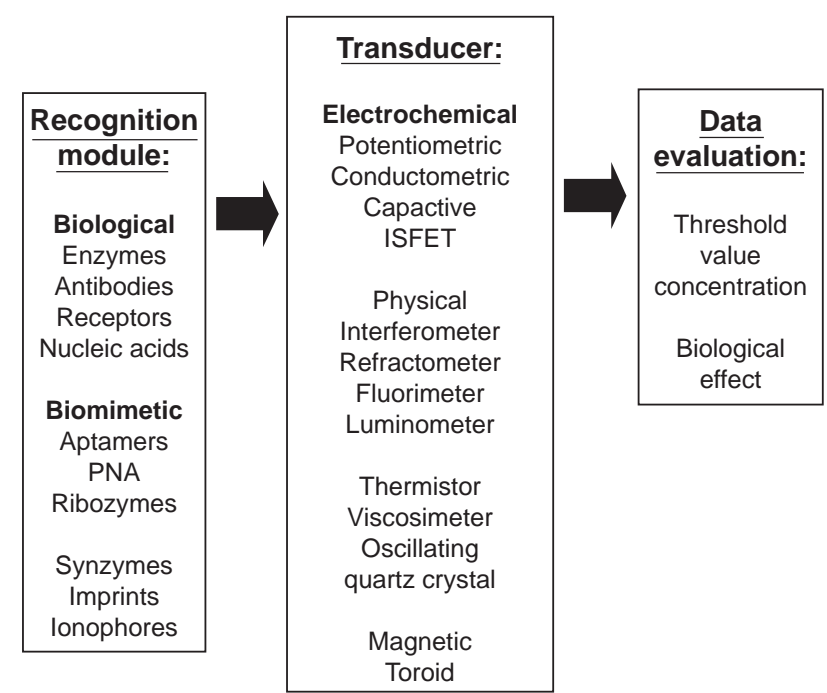

Figure 1

Principle of biosensors.

specificity and selectivity; the sensitivity, linearity and speed of the response; the dynamic range of the measurements; the possibility of calibration and accuracy.

\subsubsection{Biological Components}

The biological recognition belongs to two classes, biocatalysis when an enzyme is used, or bioaffinity when antibodies, deoxyribonucleic acid (DNA), messenger ribonucleic acid (mRNA), peptide nucleic acid (PNA) or cell receptors are used. The response of specialized microorganisms to changes in their environment is also used. The interaction between the biological recognition elements and the analyte must induce a physical or a biochemical effect that can be detected by the transducer element.

The specific biological recognition systems which have been used, are then based on the main following couples:

- enzyme/substrate;

- antigen/antibody;

- DNA/DNA;

- DNA/transcription activator;

- mRNA/DNA;

- PNA/DNA or PNA/RNA;

- microorganism/substrate;

- microorganism/toxic chemicals;

- cell receptor/hormone.

\subsubsection{Transducer Elements}

The signal transducers are devices based on electrochemical or physical (optical or acoustic) responses. They can detect the electric changes produced during an enzymic reaction (amperometric or potentiometric transducers), the heat produced during an enzymic reaction (thermometric 
transducers), the very low changes in mass induced when the biological element of recognition binds to the analyte (quartz crystal microbalance transducers), the production of light (optical transducers).

\subsection{Application Fields}

Biosensors were first developed in the medical and healthcare sectors. In other industrial areas, biosensors would most probably become a useful technology.

\subsubsection{Medicine}

New tools for real-time, rapid analyses have been developed and used in hospitals for several years: a well-known example is the measurement of glucose in blood, which allows a continuous monitoring of patients and is based on an enzymic reaction. The rapid determination of the presence of pathogens in human fluids is also of great concern and highly specific tools for detecting the presence of a specific DNA region of such microorganisms use DNA chips and are based on the capacity of DNA, immobilized on a transducer, to hybridize with a complementary DNA strand present in the patient sample (DNA/DNA interaction).

\subsubsection{Water Quality Control}

Easy-to-use, rapid and multi-response devices that monitor the presence of pathogens in water can be created by using DNA chips (based on DNA/DNA interaction). These chips allow the detection of pathogens at low concentrations in water.

\subsubsection{Control of Fermentation and Agro-Food Processes}

The detection of residual substrate concentration during industrial fermentation processes is often critical and requires on-line monitoring.

\subsubsection{Security Control}

The recent international events have led to an increasing need for biological and chemical warfare agent detection. Immunosensors to rapidly detect trinitrotoluene (TNT) have been developed. DNA chips are also under development to detect the presence of highly dangerous microorganisms, as Bacillus anthracis. The presence of toxins, ricine or botulinic toxin, or drugs could also be monitored using biosensors.

\subsubsection{Environment}

Immunosensors have been developed to detect the presence of commonly used pesticides, such as atrazine or 2,4dichlorophenoxyacetic acid (2,4-D), in water. Petroleum production, transport, refinery and distribution is a process along which there are possibilities for release of petroleum compounds in the environment. In this regard, regulation is becoming more and more severe and the cost for analyses during site investigations and remediation actions is very high. It should lead the petroleum industry to support the development of new tools for early detection in cases of pollution. The main compounds of concern, because of their toxicity for mammals, are the monoaromatics or BTEXs (benzene, toluene, ethylbenzene and xylenes), the polycyclic aromatic hydrocarbons (PAHs) and the fuel oxygenates (MTBE, ETBE, TAME).

The market of biosensors in 1996 by sector was $92 \%$ in the medical area, with $90 \%$ dedicated to the measurement of glucose (self-monitoring for diabetics) and $2 \%$ for the monitoring of other compounds (urea, lactate, etc.), $6 \%$ for the monitoring in food and drug industries, and $6 \%$ for the environment monitoring (measurement of biological oxygen demand or BOD).

We will focus the present paper on two types of biosensors that can be useful for monitoring the presence of contaminants in the environment: the bioluminescent reporter based on the use of reporter luminescence genes in genetically engineered microorganisms and the immunosensor based on the use of the interaction between antibody and antigen.

\section{BIOLUMINESCENT REPORTER}

\subsection{Principle}

The design of bioluminescent reporters relies on the ability of microorganisms to adapt to modifications in their environment, e.g. to the presence of a substrate, to an heat shock, etc., by adjusting the expression level of their genes. Genes are expressed into proteins (Fig. 2) by a two-step mechanisms, involving transcription of DNA into mRNA, then translation of mRNA into protein.

Bioluminescent bioreporters are based on genetically modified microorganisms. The genome of microorganisms is modified by including a fusion between the DNA of the promotor of interest (a genetic element regulating the gene expression) and the DNA of reporter genes whose products can emit light. The bacterial gene of interest may be involved in the degradation of a xenobiotic compound or in the response to a stress (rise in temperature, acidification of the environment, etc.). The engineered gene arising from the fusion will only be transcribed and, therefore, produce light in response to a change in the environment (e.g. the presence of the xenobiotic compound) because its expression is regulated in a very accurate way by the promotor that detect the change.

The conception of a bioluminescent bioreporter therefore requires to obtain numerous biochemical and genetic data, including the followings:

- In the case of a bioluminescent reporter to detect the presence of a xenobiotic compound, isolation of microorganisms able to degrade that compound, identification 


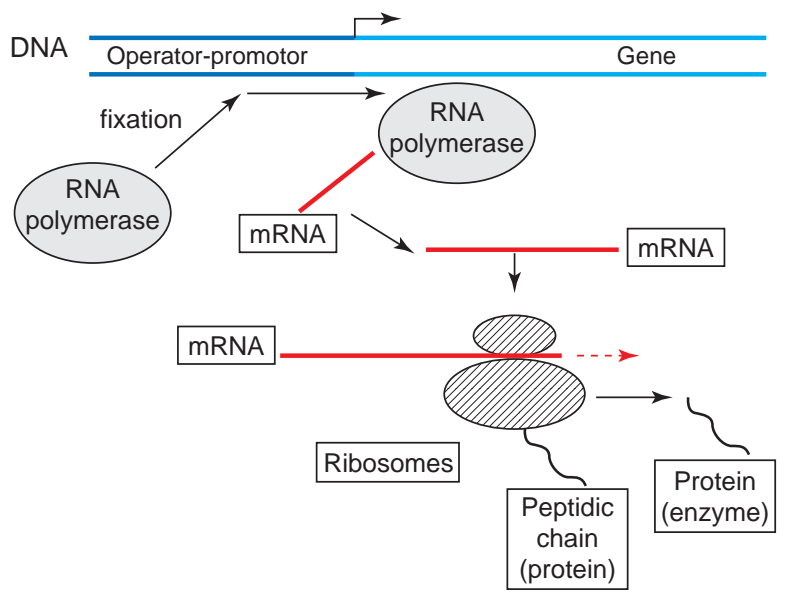

Figure 2

From DNA to enzyme. Double stranded DNA carries the genetic information (genes). The expression of the genes requires the action of RNA polymerase which binds to the DNA at the promotor, a sequence specifically recognized by the enzyme. RNA polymerase moves along the gene and transcribes the DNA sequence into mRNA, a single-stranded nucleic acid. This molecule carries the genetic information, which is translated into a protein by the cell translation machinery, including the ribosomes.

of the enzyme responsible for its degradation, elucidation of the way of its expression and, finally, isolation of the corresponding genes.

- Identification of organisms able to emit light under certain circumstances, characterization of the enzymes responsible for the emission of light and isolation of the genes encoding these enzymes.

\subsection{Regulation of Gene Expression}

Gene expression can be controlled through several mechanisms. Figure 3 describes a positive regulation. In that scheme, the regulation involves three elements: the inducer (a molecule present in the environment), the regulator (a protein) and the regulated structural gene (DNA).

- The inducer can be of multiple natures; for example, a xenobiotic compound degraded by microorganisms, etc. This case led to the development of most bioreporters: indeed bacteria have adapted to almost every environment and developed a whole metabolic diversity, including the use of numerous xenobiotic molecules as carbon and energy sources.

- The regulator is encoded by a gene, called activator in our example, and is expressed even in the absence of inducer. When the inducer is present, it binds to the regulator and stimulates the transcription.

- The regulation involves the promoter sequence of the regulated genes. The regulator, bound to the inducer, adopts an active conformation and allows the transcription of the regulated genes into a messenger RNA (mRNA). The mRNA will be then translated into proteins or enzymes. Thus, the bacteria will be able to adapt to the presence of the xenobiotic compound.

This system of recognition can be very specific. For example, a bioreporter that was designed by Shetty et al. (1999) and used the genes degrading L-arabinose, allowed these authors to identify L-arabinose quantitatively and selectively in a complex mixture of L-, D- arabinose and other sugars.

a) No substrate

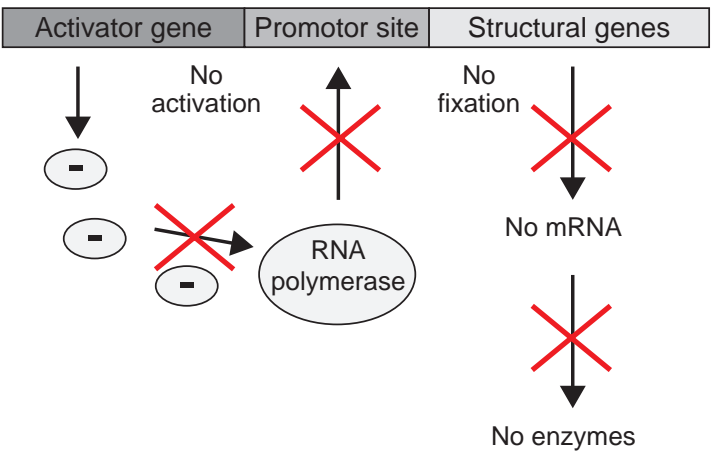

b) Substrate

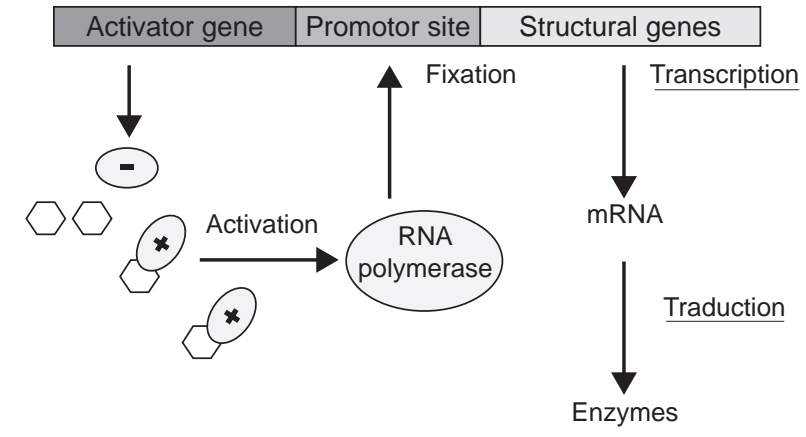

Figure 3

Positive regulation of gene expression in microorganisms. The activator protein (in grey) allows the binding of the RNA polymerase onto the promotor in the presence of substrate. In this way the structural genes are expressed only in presence of the substrate.

\subsection{Bioluminescence Genes and Proteins}

A wide range of genes encodes proteins that allow the emission of light, either in prokaryotes or eukaryotes.

The most frequently used are the followings:

- The luc genes of the glow worm, which encode a luciferase, an enzyme that produces visible light when luciferine is added to the medium. 
- The genes of the jellyfish Aequorea victoria that encode aequorin, a protein that emits a blue light when calcium ions are provided.

- The genes of A. victoria that encode the green fluorescent protein (GFP). This protein does not need a substrate, and emits light when excited with UV light.

- The genes encoding the uroporphyrinogene III methyltransferase (UMT), which emits red-orange light after excitation with ultraviolet light.

- The lux genes, a generic name given to the genes encoding different bacterial luciferases. These enzymes catalyze a reaction and emit light. We will detail it later on.

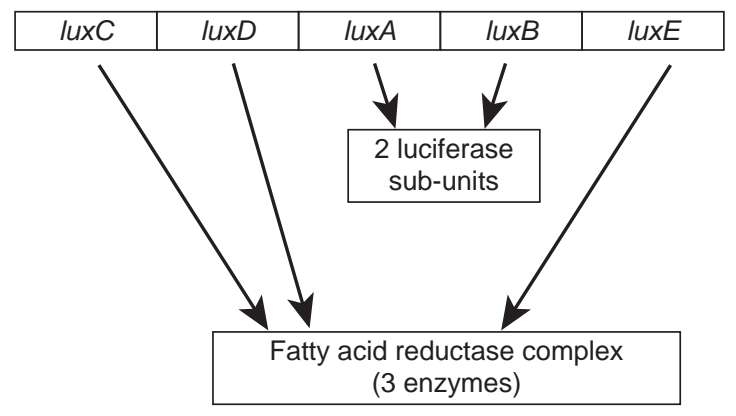

a)

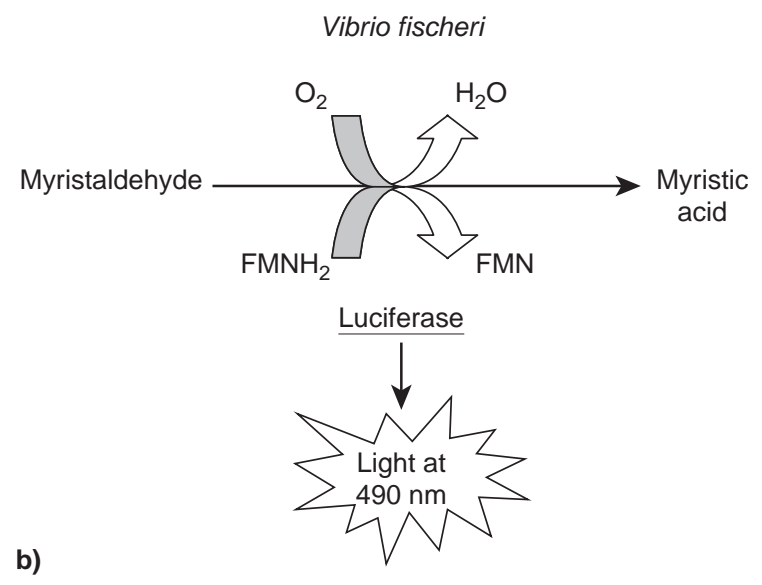

Figure 4.

System of the lux genes of Vibrio fischeri. a) Structure of the lux genes; b) Enzymatic reaction producing light. The lux genes are organised in an operon.

The luxCDE genes encode a fatty acid reductase complex allowing the production of myristaldehyde. The luxAB genes encode the luciferase, which catalyses the oxidation of the myristaldehyde to myristic acid. This enzyme produces light at $490 \mathrm{~nm}$.

The lux genes isolated from V. fischerii (Fig. 4a) are the most frequently used for the construction of bioluminescent bioreporters. The $l u x A$ and $l u x B$ genes encode the luciferase, while the $\operatorname{lu} x C, \operatorname{luxD}$ and $\operatorname{luxE}$ genes encode an enzymic complex, able to produce the substrate of luciferase: the myristaldehyde. They are used in two ways:

- luxAB box, a combination that allows the emission of light but requires the addition of myristaldehyde;

- luxCDABE box, a combination that allows the emission of light without the need for any additional reagent.

The enzymic reaction involving the luciferase is presented in Figure $4 \mathrm{~b}$. This reaction leads to the formation of myristic acid and light emission. Microorganisms having these genes can emit light.

\subsection{Bioluminescent Reporters}

Two steps are required to create such a reporter:

- a fusion between the DNA elements controlling the expression of the gene of interest in microorganisms and the reporter genes (lux genes);

- the introduction of such engineered genes into a microorganism for the detection of the xenobiotic compound by a whole-cell bioluminescent reporter.

\subsubsection{Creation of the Gene Fusion}

Double stranded DNA can be cut by restriction enzymes. These enzymes cut the DNA at specific sites and are used to carry out genetic constructions. The DNA products of such a restriction have ends that can be joined to other DNA fragments treated with the same restriction enzyme thanks to specialized enzymes, the ligases. Thus, by using these two types of enzymes, it is possible to create a chimeric DNA fragment carrying the promotor sequence of the gene of interest fused with the reporter genes (lux genes) (Fig. 5).

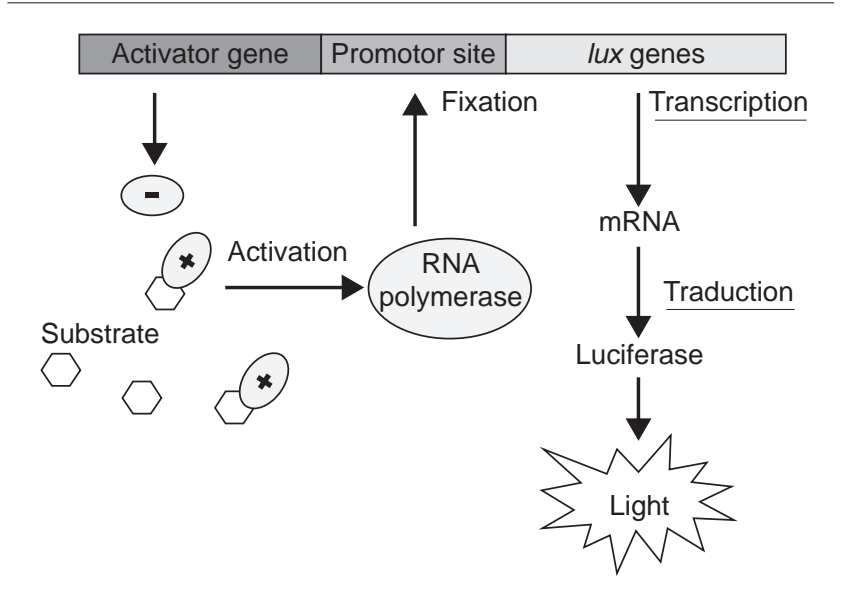

Figure 5

Principle of gene fusions.

\subsubsection{Creation of the Bioreporter}

Then, the engineered DNA fragment must be introduced into a bacterium in a stable way (it means without being lost 
through generations). The recipient bacterial strain will be immobilized by different means, for example on a membrane recovered by a gel. The samples will be directly injected in contact with the membrane, and the bacterial response leading to the emission of light will be detected using a photosensitive cell and quantified. The answer is proportional to the concentration in xenobiotic compound if the biosensor is valid, which requires a specific step (see Section 6).

The creation of bioreporters that use living microorganisms, requires to work only with aqueous samples so as to expose the plasmatic membrane of the bacteria, which restricts these analytic tools to the detection of soluble compounds.

Such a biocaptor was developed by the Center for Environmental Biotechnology (CEB) (Knoxville, Tennessee). The size of the prototype makes it an ideal tool for measurements on the spot (Fig. 6).

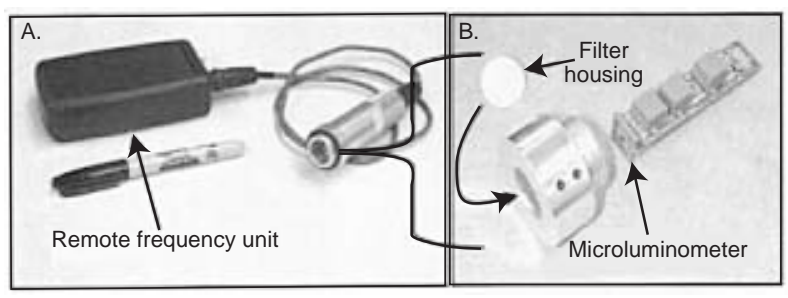

Figure 6

Prototype of light signal recorder developed by the $C E B$ and the Oak Ridge National Laboratory. a) Luminometer, note that the size is a pen's one; b) Filtration unit carrying the bacteria including the reporter genes.

\section{IMMUNOSENSORS}

\subsection{Principle}

All immunoassays involve the recognition between an antigen and its corresponding antibody. Antibodies are proteins, produced by mammals in response to foreign elements (bacteria, viruses, chemicals, etc.). This recognition is very specific in general. In an immunoassay, the binding of the analyte (or antigen) to an antibody reflects its concentration in the sample and, therefore, can allow its quantification. When the bioreceptor of a biosensor is an antibody or an active portion of an antibody, such a biosensor is generally called an immunosensor. Most immunoassays do not constitute biosensors because they do not satisfy some of their general properties (see Paragraph 1.1). In particular, they rarely function without addition of external reagent and therefore cannot give a continuous response. Recently, reagentless fluorescent immunosensors that satisfy all the characteristics of real biosensors, have been described by one of us (Renard et al., 2002; Renard et al., 2003). However, we will concentrate the remainder of this paragraph to the most common immunassays, for reasons of simplicity.

The principle of immunoassays is simple, but putting it in practice required to overcome several problems:

- It is not easy to produce antibodies against relatively small molecules and the use of immunoassays for the detection of chemicals has first required to develop strategies for such a production.

- The conception of an immunoassay requires that the antibody production is reliable and sustainable. If antibodies are produced in animals (polyclonal antibodies, pAbs), the availability and reliability of their production is not ensured. Two technologies allow the production of homogeneous and constantly available antibodies: the hybridoma technology for the production of monoclonal antibodies (mAbs), which is an expensive and time consuming technology, and the production of recombinant antibodies (the recognition module of antibodies), which allows one to reduce the costs.

- The binding between antibody and antigen does not generate any measurable signal. Different types of reporter systems are used to transform the binding event into a measurable signal, and they involve different types of labeling: the product of an enzymic reaction in enzyme immunoassays (enzyme-linked immunosorbent assays, ELISAs), or the production of light in the fluorescent immunoassays.

- Two types of measurements are possible, competitive or non-competitive. The choice depends on the compound analyzed and on the type of labeling chosen.

\subsection{Antibody Production}

\subsubsection{Coupling of the Target Molecule}

The target molecule is often a small molecule (MW < 1000), unable to produce an immune response. To obtain the production of antibodies with such small molecules requires

1) $R-X$

2) $\mathrm{R}-\mathrm{X}-\left(\mathrm{CH}_{2}\right)_{\mathrm{n}}-\mathrm{COOH}$

3)

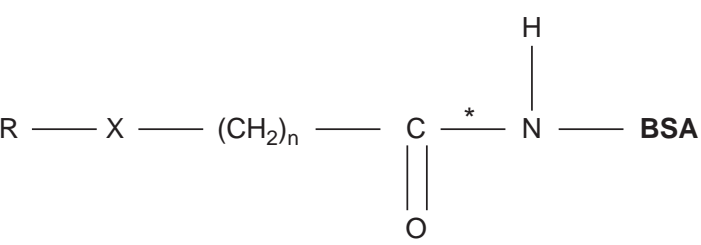

Figure 7

Engineering of a molecule for production of antibodies. 1) molecule to analyze; 2) molecule coupled to an hapten; 3 ) hapten-carrier conjugate.

BSA: bovine serum albumine; *: peptid bond 
their covalent attachment to larger molecules, e.g. a carrier protein like bovine serum albumin (BSA). A scheme for such a coupling is presented in Figure 7. It allows the obtention of a hapten-carrier conjugate, which can be used for immunization and the generation of antibodies (Hennion and Barcelo, 1998).

\subsubsection{Production of Antibodies}

The most useful and stable antibodies belong to the class of immunoglobulins $\mathrm{G}$ ( $\mathrm{IgG}$ ). Their typical structure is presented in Figure 8. They are composed of two heavy peptidic chains (450 aminoacids) and two light peptidic chains (212 amino-acids). In both types of chains, there are domains with highly conserved peptidic sequences (fraction able to crystallize or Fc portion) representing about $90 \%$ of the antibody and domains with a high variability in their peptidic sequence (fragment antigen binding or Fab portion). This latter domain provides the specificity for the binding to the antigen. Disulfide bridges between the heavy and light chains and inside the chains stabilize the structure of the antibody protein.

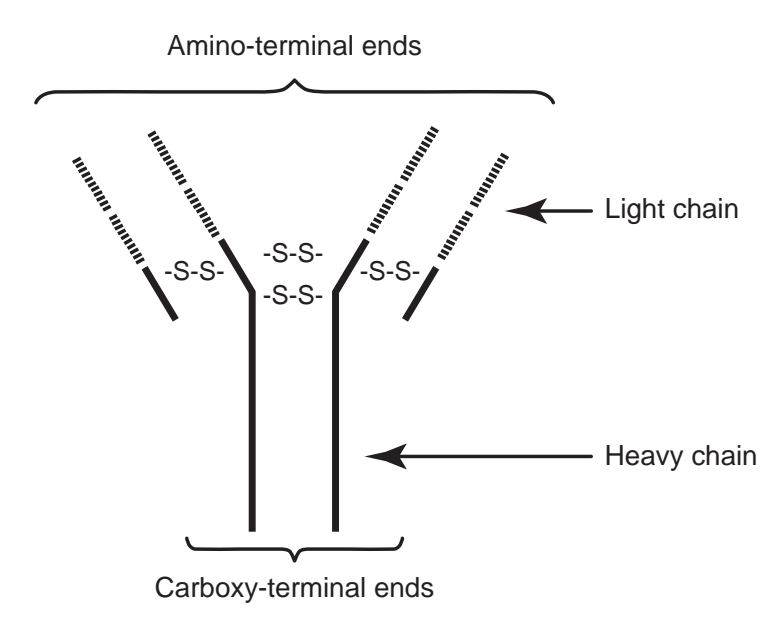

Figure 8

General structure of an antibody. Variable region of the peptidic sequence (hatched), constant region of the peptidic sequence (plain), -S-S-: disulfure bridge. The amino-terminal domains are shaped to allow specific interactions with the corresponding antigen.

Polyclonal antibodies (pAbs) can be produced by injecting the hapten-carrier conjugate to animals, but the use of pAbs can cause cross-reactivity and be source of problems by decreasing the specificity. They are two ways to improve the quality of antibodies for their subsequent use in immunoassays:

- Production of monoclonal antibodies: in this technique, the antibodies are produced on special cells (hybridoma cells) that are obtained from the fusion of two types of cells, B-lymphocytes that are able to produce antibodies but are not able to divide indefinitely and myeloma cells which are tumorigenic and, therefore, able to divide indefinitely. The resulting hybridoma cells can be grown on a lab-scale and allow the stable production of monoclonal antibodies (mAbs) for a specific antigen. Nevertheless, the cost of mAbs production is high and may hamper their use in immunoassays for environmental pollutants (Greenan et al., 2003).

- Production of recombinant antibodies: as mentioned above, only the variable fragment $\mathrm{Fv}$ of the Ab molecule is effective in the interaction between antibody and antigen. The methods of molecular biology allow one to isolate (i.e. to clone) and express specific DNA fragments encoding a single-chain $\mathrm{Fv}$ ( $\mathrm{scFv}$ ) of the antibody molecule in microorganisms like Escherichia coli. Thus, one can produce recombinant antibodies that can be used in immunoassays, at a low cost.

\subsection{Different Types of Immunoassays}

The immunoassays can be used in competitive or noncompetitive ways.

\subsubsection{Competitive Immunoassays}

They are heterogeneous immunoassays requiring washing steps in the experimental procedure.

- First possibility: The antibodies are immobilized on the solid support and interact with the corresponding antigens (molecule to analyze) if present in the sample or with added engineered labeled antigens in a fixed amount.

In that scheme, added labeled antigens compete with antigens present in the sample for a given amount of antibodies (Fig. 9). When there is no antigen in the sample, the antibody sites are saturated by the labeled antigen and the response is at the maximum. It decreases with the concentration of antigen in the sample.

This approach is often followed when the antigen is a small molecules that can be labelled with a fluorescent group. In that case, both the unlabelled and labelled antigens have similar mobilities.

- Second possibility: An analog of the antigen is immobilized on the support and can compete with the antigen, if present in the sample, for the binding to a fixed amount of free labeled antibody (Fig. 10). A washing step allows one to eliminate the complex formed in solution between the antigen and the labeled antibody; the measurement is performed on the labeled antibodies bound to the immobilized antigen. As above, the maximum response is obtained when there is no antigen (i.e. no pollutant) in the sample.

The antibody is generally conjugated with an enzyme, used as a reporter, in this approach. 


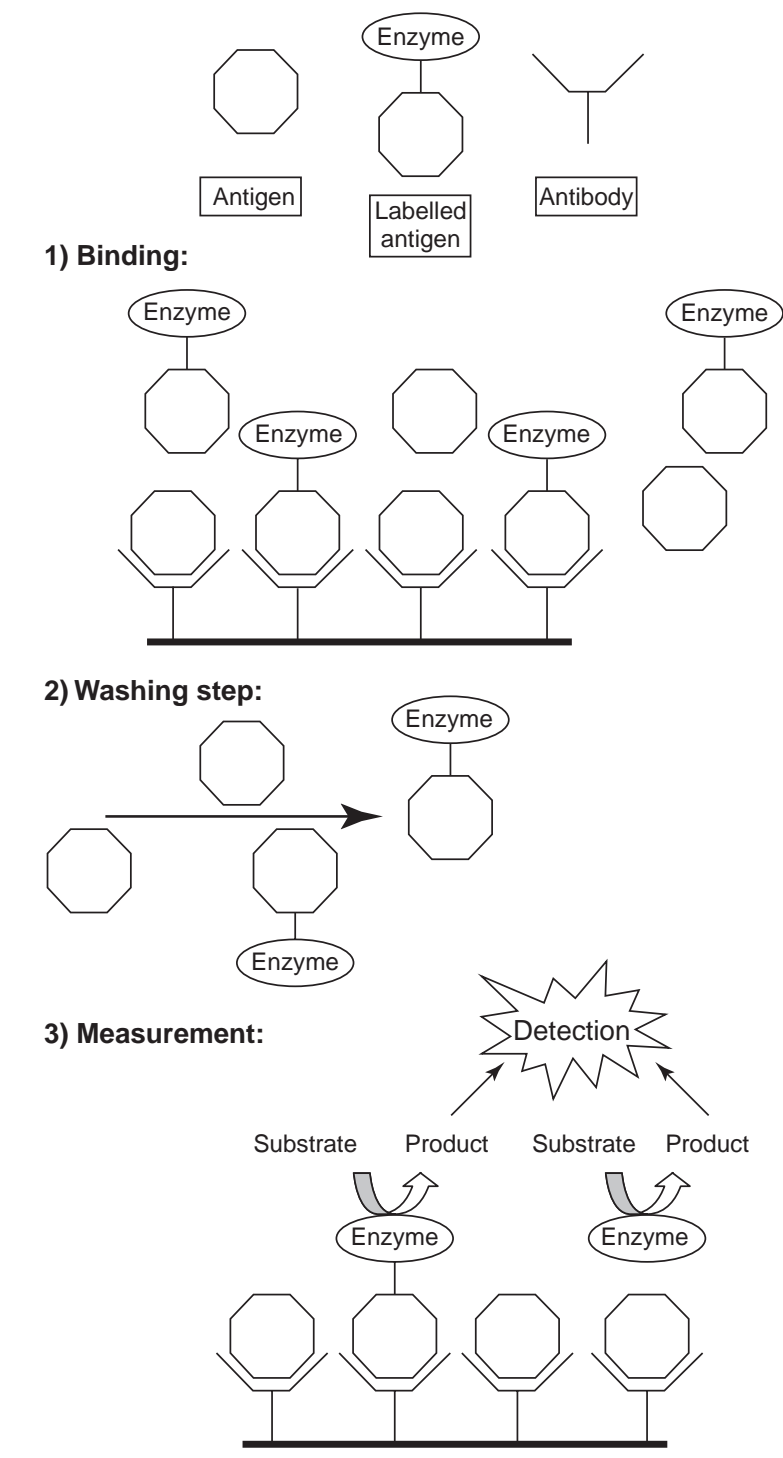

Figure 9

Competitive immunoassay.

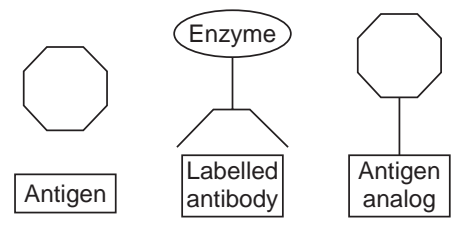

1) Binding:
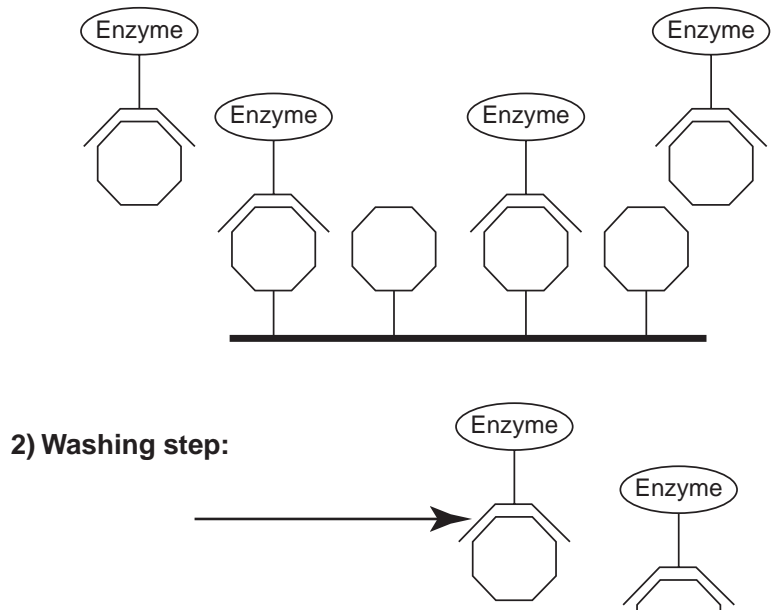

3) Measurement:
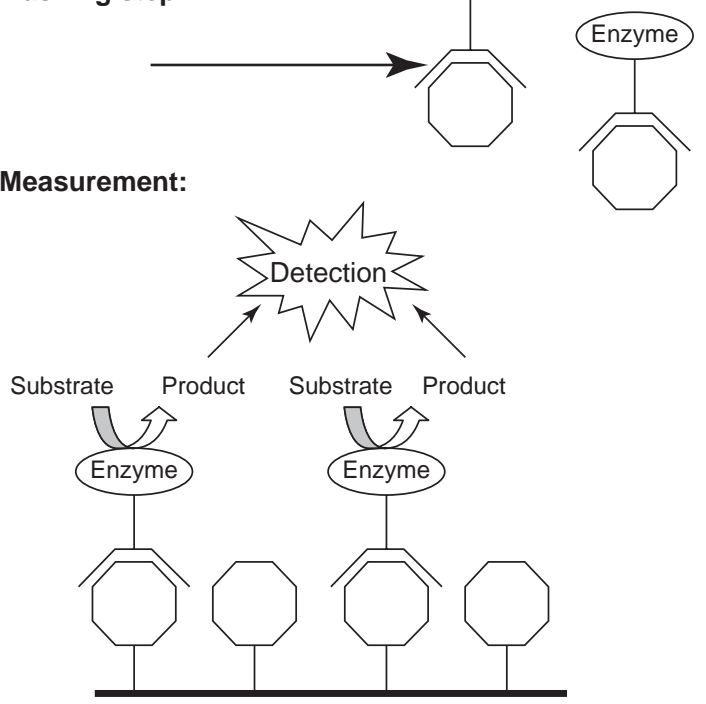

Figure 10

Competitive immunoassay.

\subsubsection{Non-Competitive or "Sandwich" Immunoassay}

This homogeneous immunoassay consists of three successive reactions:

- the antibodies immobilized on the solid support interact with the corresponding antigen if present in the sample;

- labeled antibodies are added and interact with the antigens bound to the immobilized antibodies;

- the emitted signal is measured.

In that case, the immobilized antibodies (capture antibodies) and the labeled antibodies are directed towards different parts of the antigen molecule, which imposes to work with antigens that are big enough to possess two different antigenic sites (Fig. 11).
In this method, the response does not depend on the affinity of the antigen for the antibody and is proportional to the antigen concentration in the sample.

\section{MODE OF SAMPLE INJECTION}

Flow-injection analysis (FIA) is a technology that is commonly used in various sensors, including immunosensors. This technology allows automated handling of samples and reagents. It consists in the analysis of a chemical compound by inserting a sample into a carrier stream of reagent using highly automated systems of valves prior to detection. 


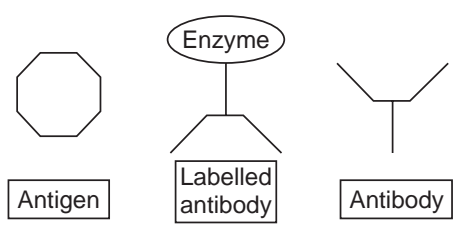

1) Binding of antigen to antibody:

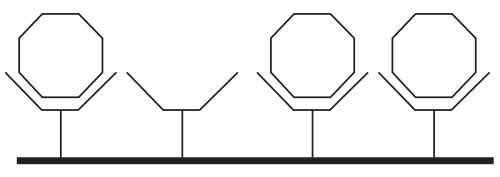

2) Secondary binding of antigen to the labelled antibody:



3) Measurement:

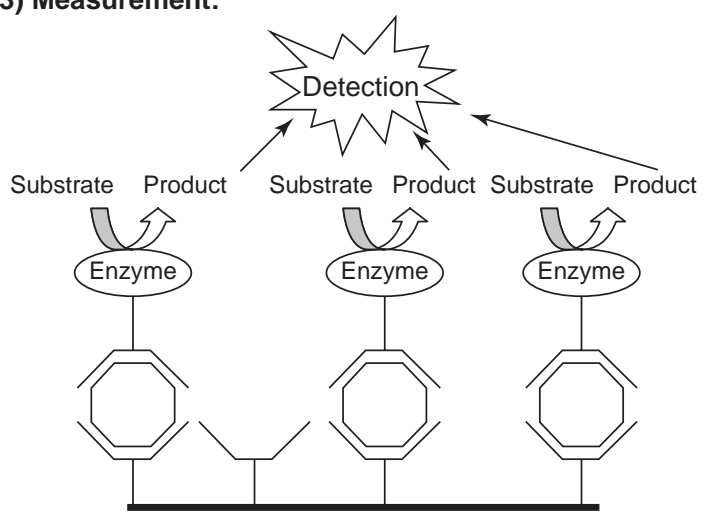

Figure 11

Non-competitive or "sandwich" immunoassay.

The FIA technology allows one to perform continuous measurements, to obtain a high reproducibility and to work with small volumes of samples. The corresponding devices are very flexible since they can be easily coupled to various detectors for the measurements of the emitted signal.

\section{MODE OF DETECTION}

The measurement of the signal depends on the type of reporter (labeling). Electrochemical and optical detection, used in immunosensors and bioluminescent sensors, are only some of all the detection systems that were imagined and tested (Mallat et al., 2001; Pearson et al., 2000).

\subsection{Electrochemical Defection}

Electrochemical measurements are often used in immunoassays when the reporter is an enzyme. In that case, different classes of enzymes (oxidoreductase, etc.) that can generate the production of electroactive species can be used. The detection is performed in two different ways.

\subsubsection{Amperometry}

It consists in monitoring a current. The enzymatic reaction produces an electroactive species, which is driven to an electrode because of the application of a potential at a fixed value. The response is proportional to the concentration of the analyzed compound. Such electrochemical measurements can be used in competitive and non-competitive immunoassays.

\subsubsection{Potentiometry}

In that case, the electrodes are specific for the electroactive species, which is attracted. It generates a potential that can be measured. No current is applied in such a sensor and the response is related logarithmically to the concentration of electroactive species that is produced by the enzymic reaction.

\subsection{Optical Detection}

The reporter in that case emits light and the change is measured using one of the optical properties: intensity, phase, polarization, wavelength or spectral distribution. The advantage of optical transduction is that the signal is measured in a non-destructive way (Pearson et al., 2000). When intensity is measured, the concentration in analyte is proportional to the quantity of emitted light.

\section{VALIDATION PROCESS}

The validation step requires the comparison of these new analytical devices to classical ones. The following points have to be precisely determined using the different prototypes:

- The detection limits, especially the lower limit of detection, and the sensitivity.

- The determination of possible interferences with other compounds present in the environment, i.e. the selectivity.

- The delay between the contact with the analyte and the monitoring of the signal, i.e. the time of response.

- The determination of the number of analyses that can be performed without regenerating/replacing the biological elements.

- The influence of various physical conditions encountered in the environment ( $\mathrm{pH}$, salinity, temperature, etc.) on the response. 
The results that are obtained by these ways, are compared to those obtained with the usual analytical devices (GC, GC/MS, etc.).

\section{APPLICATIONS TO PETROLEUM COMPOUNDS DETECTION}

Numerous bioluminescent reporters have been built to detect various compounds.

The Center of Environmental Biotechnology (CEB) has developed several biocaptors up to the prototype to analyze various pollutants found in water and, among them, some petroleum compounds, BTEXs and naphthalene (Table 1). Other groups have also published results concerning the detection of naphthalene; recently, Valdman et al. (2004) built a reporter able to detect naphthalene with a response time of $19 \mathrm{~min}$ and with a lower limit of naphthalene detection of $20 \mu \mathrm{g} \cdot \mathrm{l}^{-1}$, the health advisory limit for naphthalene fixed by United States EPA (US Environmental Protection Agency) being $20 \mu \mathrm{g} \cdot \mathrm{l}^{-1}$.

TABLE 1

Bioluminescent biocaptors developed at the "Center for Environmental Biotechnology" (Knoxville, Tenessee)

\begin{tabular}{l|c}
\hline \multicolumn{1}{c|}{ Detected compound } & References \\
\hline Naphthalene & Ripp et al., 2000 \\
Phenol & Abd-El-Haleem et al., 2002 \\
Toluene & Applegate et al., 1997 \\
BTEXs & Applegate et al., 1998 \\
PCBs & Layton et al., 1998 \\
Trichloroethylene & Applegate et al., 1997 \\
2,4-dichlorophenoxyacetic acid (2,4-D) & Hay et al., 2000 \\
Salicylic acid & Heitzer et al., 1992 \\
\hline
\end{tabular}

IFP in collaboration with the $C E B(\mathrm{PhD}$ project) intends to develop a bioreporter to detect fuel ethers in water. Indeed, MTBE has been shown to be responsible for groundwater pollution in United States (Fayolle et al., 2001). In Europe, the monitoring of groundwater is required to evaluate the level of MTBE contamination. The creation of a whole-cell bioluminescent reporter specific for MTBE, ETBE and TAME would enable such a monitoring at lower cost and more easily than with classical analytical methods.

Immunosensors to detect petroleum compouds have also been built. Fähnrich et al. (2003) developed an amperometric immunosensor for phenanthrene detection at $300 \mathrm{mV}$ with the alkaline phosphatase enzyme and a detection limit of 800 parts-per-trillion (ppt). Gobi and Miura (2004) have reported the detection of benzo(a)pyrene $(\mathrm{BaP})$ with immunosensor chips working by an indirect competitive immunoreaction method and it allows the detection of $\mathrm{BaP}$ at a concentration as low as $10 \mathrm{ppt}$ with a response time of $15 \mathrm{~min}$.

\section{CONCLUSIONS}

As shown, the sensitivity and selectivity of the numerous existing biosensor prototypes are very high and more improvements are expected. The trends for the development of biosensors are directed towards a miniaturization of the devices, an integration of the advances in technological areas as surface chemistry and transduction systems. Moreover, the present great interest and the expected advancements in nanotechnology research will probably allow to increase dramatically the possibilities of use of biosensors. The results of such an evolution is still difficult to anticipate but should allow to overcome the restrictions of both the manufacturers of the area and the restriction of the users. Actually, the competition with classical devices of analyses is the present and, probably, the greatest challenge in the development of such new devices, especially for their use in environment monitoring.

\section{REFERENCES}

Abd-El-Haleem, D., Ripp, S., Scott, C. and Sayler, G.S. (2002) A luxCDABE-Based Bioluminescent Bioreporter for the Detection of Phenol. J. Ind. Microbiol. Biotech., 29, 233-237.

Applegate, B., Kelley, C., Lackey, L., Mc Pherson, J., Kehrmeyer, S., Menn, F.M., Bienlowski, P. and Sayler, G. (1997) Pseudomonas putida B2: a tod-lux bioluminescent reporter for toluene and trichlorethylene co-metabolism. J. Ind. Microbiol. Biotech., 18, 4-9.

Applegate, B.M., Kehrmeyer, S.R. and Sayler, G.S. (1998) A Chromosomally Based tod-lux Whole-Cell Reporter for Benzene, Toluene, Ethylbenzene, and Xylene (BTEX) Sensing. Appl. Environ. Microbiol., 64, 2730-2735.

Fähnrich, K.A., Pravda, M. and Guilbault, G.G. (2003) Disposable Amperimetric Immunosensor for the Detection of Polycyclic Hydrocarbons (PAHs) Using Screen-Printed Electrodes. Biosensors Bioelectronics, 18, 73-82.

Fayolle, F., Vandecasteele, J.P. and Monot, F. (2001) Microbial Degradation and Fate in the Environment of Methyl Tert-Butyl Ether and Related Fuel Oxygenates. Appl. Microbiol. Biotechnol., 56, 339-349.

Gobi, K.V. and Miura, N. (2004) Highly Sensitive and Interference-Free Simultaneous Detection of Two Polycyclic Aromatic Hydrocarbons at Parts-Per-Trillion Levels Using a Surface Plasmon Resonance Immunosensor. Sensors Actuators, in press, available on line.

Greenan, K., Strachan, G., Porter, A.J., Killard, A.J. and Smyth, M.R. (2003) Atrazine Analysis Using an Amperometric Immunosensor Based on Single-Chain Antibody Fragments and Regeneration-Free Multi-Calibrant Measurement. Anal. Chim. Acta, 500, 287-298.

Hay, A.G., Applegate, B.M., Bright N.G. and Sayler, G.S. (2000) A Bioluminescent Whole-Cell Reporter for Detection of 2,4dichlorophenoxyacetic Acid and 2,4-dichlorophenol in Soil. Appl. Environ. Microbiol., 66, 4589-4594.

Heitzer, A.O., Webb, O.F., Thonnard, J.E. and Sayler, G.S. (1992) Specific and Quantitative Assessment of Naphthalene and Salicylate Bioavailability by Using a Bioluminescent Catabolic Reporter Bacterium. Appl. Environ. Microbiol., 58, 1839-1846.

Hennion, M.C. and Barcelo, D. (1998) Strengths and Limitations of Immunoassays for Effective and Efficient Use for Pesticide 
Analysis in Water Samples: a Review. Anal. Chim. Acta, 362, 3-34.

Layton, A.C., Muccini, M., Ghosh, M.M. and Sayler, G.S. (1998) Construction of a Bioluminescent Reporter Strain to Detect Polychlorinated Biphenyls. Appl. Environ. Microbiol., 64, 50235026.

Mallat, E., Barcelo, D., Barzen, C., Gauglitz, G. and Abuknesha, R. (2001) Immunosensors for Pesticide Determination in Natural Waters. Trends Anal. Chem., 20, 124-132.

Meighen, E.A. (1991) Molecular Biology of Bacterial Bioluminescence. Microbiol. Rev., 55, 123-42.

Pearson, J.E., Gill, A. and Vadgama, P. (2000) Analytical Aspects of Biosensors. Ann. Clin. Biochem., 37, 119-145.

Renard, M., Belkadi, L., Hugo, N., England, P., Altschuh, D. and Bedouelle, H. (2002) Knowledge-Based Design of Reagentless Fluorescent Biosensors from Recombinant Antibodies. J. Mol. Biol., 318, 429-442.

Renard, M., Belkadi, L. and Bedouelle, H. (2003) Deriving Topological Constraints from Functional Data for the Design of
Reagentless Fluorescent Immunosensors. J. Mol. Biol., 326, 167175.

Ripp, S., Nivens, D.E., Ahn, Y., Werner, C., Jarrell, J., Easter, J.P., Cox, C.D., Burlage, R.S. and Sayler, G.S. (2000) Controlled Field Release of a Bioluminescent Genetically Engineered Microorganism for Bioremediation Process Monotoring and Control. Environ. Sci. Technol., 34, 846-853.

Shetty, R.S., Ramathan S., Badr, I.H., Wolford, J.L. and Daumert, S. (1999) Green Fluorescent Protein in the Design of a Living Biosensing System for L-arabinose. Anal. Chem., 71, 763768.

Thevenot, D.R., Toth, K., Durst, R.A. and Wilson, G.S. (2001) Electrochemical Biosensors: Recommended Definitions and Classification. Biosens. Bioelectron., 16, 121-131.

Valdman, E., Valdman, B., Battaglini, F. and Leite, S.G.F. (2004) On-Line Detection of Low Naphtalene Concentrations with a Bioluminescent Sensor. Process Biochem., 39, 1217-1222.

Final manuscript received in March 2005 or distributed for profit or commercial advantage and that copies bear this notice and the full citation on the first page. Copyrights for components of this work owned by others than IFP must be honored. Abstracting with credit is permitted. To copy otherwise, to republish, to post on servers, or to redistribute to lists, requires prior specific permission and/or a fee. Request permission from Documentation, Institut français du pétrole, fax. +33147527078 , or revueogst@ifp.fr. 